\title{
Evaluating what matters: an evaluation tool for vulnerability risk assessments in local climate change adaptation planning
}

\author{
Obakeng A. Sethamo ${ }^{\mathrm{a}, \mathrm{c}} \&$ Marie K. Harder*a,b \\ a Department of Environmental Science and Engineering, Fudan University, Shanghai, \\ People's Republic of China \\ ${ }^{b}$ School of Computing, Engineering and Mathematics, University of Brighton, Brighton, UK \\ 'Southern African Science Service Centre for Climate Change and Adaptive Land \\ Management (SASSCAL), Namibia, SADC \\ *Corresponding author: m.k.harder@brighton.ac.uk
}

\begin{abstract}
The United Nations Framework Convention on Climate Change has set out guidance to move countries forward via National Adaptation Plans, but many of these have proven nonimplementable because they are generic and lack details of community needs. Here we review what vulnerability risk assessments (VRA) characteristics are considered desirable but absent, and thence develop an Evaluation Tool, for systematically analyzing VRAs as used for adaptation planning at the local level. We test it experimentally on an innovative VRA process claiming better outcomes - it uses a pre-process of crystallizing shared-values of participants before considering climate issues. The evaluation results show that the Tool can successfully discriminate the quality of this approach and captures many distinct characteristics and differences. The Tool, which can also be a practitioner's checklist, should thus be helpful in identifying and accelerating improvements in VRAs, and hence in adaptation planning, with affiliated local and global benefits.
\end{abstract}

Key words: national adaptation plans; values-based approach; vulnerability risk assessment; climate change; local community 


\section{Introduction}

Climate change impacts require forward planning for adaptation considerations, but the precise way this is taken forward will vary depending on the scale being considered (e.g. national, regional), and competing priorities. In developing countries where climate-related risks are closely intertwined with non-climatic factors, resources are very limited, and uncertainty about the impacts very large, a vulnerability-based approach is deemed the most useful for adaptation planning (Fussel 2007). Vulnerability risk assessments (VRAs) focus on understanding how stakeholders did, can, and will deal with climate change impacts (Masundire et al. 2015). They are designed to identify the top priority areas for action, and to consider the effectiveness of specific interventions. When carried out at a local level, VRAs require the input of information about local people, livelihoods and governing institutions, so that any adaptation plans are directly linked to their related activities (Fussel 2007). Vulnerability risk assessments (VRAs) focus on determining the degree to which the system of interest (e.g. community, country) is susceptible to, and unable to cope with, the adverse effects of single or multiple pressures, currently and into the future (Hay and Mimura 2013). Especially when they are applied in social, cultural and related contexts, these assessments tend to focus on the underlying determinants of vulnerability, such as livelihood systems, poverty and marginalisation (Hay and Mimura 2013). The VRA approach aims to support a change in behavior that will shield people against the impacts of climate change, and it is understood that this cannot be done without understanding local contexts.

The United Nations Framework Convention on Climate Change (UNFCCC) has set out guidance for countries to move forward in their planning via National Adaptation Programs of Action (NAPAs), but as early as 2009, Westerhoff and Smit (2009) reported that these programs, and National Communication Reports to the UNFCCC, have failed to become implementable because they "tend to be too generic and lack micro level understanding, devoid of local communities' concerns, needs, and visions". In their analysis of the quality of national adaptation plans and opportunities for improvement Woodruff and Regan (2018) also found that public participation is the weakest principle of the NAPs and represent an opportunity for public engagement, feedback in the process and improvements for future plans. They also encouraged the continued research and development of approaches to evaluate and track adaptation progress (Woodruff and Regan 2018).

There have been many discussions of the underlying reasons for the barriers to producing implementable plans, in literature of both researchers and practitioners. However, nine years later, the UNFCC reported that the problems were still considerable, specifying them further: "Current assessments are insufficiently articulated to indicate which communities, groups and ecosystems are the most vulnerable, and this can also lead to challenges in balancing the needs of vulnerable communities, groups and ecosystems with development needs (UNFCCC 2018)."

In this paper we review the literature to understand more comprehensively what characteristics of VRAs are considered desirable and absent, and we use those to guide our development of an evaluation tool that can be used to analyze VRA reports in a systematic manner. We then involved field experts in improving our prototype evaluation tool, and tested it on a candidate 
VRA innovation used in four villages against standard VRAs in two control villages. The aim of the evaluation tool is to both to provide transparent and immediately useful information to the providers and users of VRAs on how to improve them, and to provide a mechanism by which innovations in VRAs can be readily evaluated for any effectiveness. The tool should be helpful in accelerating improvements in VRAs, and thus in climate change adaptation planning, with the affiliated local and global benefits. Finally, a robust VRA will examine climate exposure, climate sensitivity factors and adaptive capacity (Dawson et al. 2011), ultimately providing insight into potential causes of vulnerability (Small-Lorenz et al. 2013) and guide response action. Therefore, the tool should integrate the elements of exposure, sensitivity and adaptive capacity (IPCC 2007) in VRA assessments.

Below, we set out our key learning about desired characteristics, the method for developing the assessment tool, the evaluation of the prototype with field experts, and the final test of it on a candidate VRA innovation used in four villages.

\subsection{A shift in the role of Vulnerability Risk Assessments}

The UNFCCC's approach via National Adaptation Programs of Action (NAPAs) was an important global driver to accelerate action on climate change worldwide, but the outcomes have not been proving implementable (Westerhoff and Smit 2008). The approach was framed as a top-down, scenario-driven approach, typical of the early culture of adaptation planning which placed emphasis on 'scientific knowledge'. At a national level, action was entrusted to national institutions to lead the NAPAs, and financial mechanisms were aimed at delivering climate change actions developed in them. A growing dissatisfaction with such a top-down scenario-driven approach developed as it became clear that; "no action taken at national, regional or international levels will be effective unless there is a concomitant reduction in the vulnerabilities of people and communities on the ground" (IFRC 2009). Instead of using global model scenarios far into the future, it was suggested that the assessments should examine vulnerability to current climate variability and extremes, as well as the current adaptation strategies, policies and measures, based on actual experience at different scales (Aalst et al. 2007).

This shift of emphasis to other scales besides national, and more specific contexts at each scale, signaled a slow shift in emphasis in approaches: local stakeholders now needed to be deeply involved in each case. The strict requirement that vulnerability risk assessments (VRAs) involve local stakeholders was also viewed as an essential step for predicting the impacts of climate change, and assessing adaptive capacity within social and social-ecological systems (Romieu et al. 2010; Warrick 2007). This came from a realization that the risk and damage associated with climate events result more from conditions on the ground than from climate variability or change, and that climate events or trends are transformed into differentiated outcomes via social structure (Ribot 2010).

This sliding shift in the role of VRAs was matched by a shifting discussion of the desirable characteristics of VRAs, and effective climate change vulnerability risk assessments (VRAs) are now considered to comprise both a process and an outcome in the form of a VRA Report. 
Overall, VRAs seek to synthesize the best available evidence associated with the current and future climate conditions and impacts, the adaptive capacity of targeted communities and organizations, and the potential programmatic options to address the resulting vulnerability (Wood et al. 2017). They are expected to need to use participatory methods to produce valid processes of identification and prioritization of existing and future vulnerabilities, risks, capacities and ambitions (Masundire et al. 2015).

\subsection{The increasing role of participation in VRAs}

Westerhoff and Smit (2008) had reported that UNFCCC adaptation plans failed to become implementable because they "lack micro level understanding, devoid of local communities' concerns, needs, and visions". This was interpreted by some as an inability of VRAs to engage with socio-ecological systems which cannot be contained by current assessment, management, and planning tools - thus resulting in lack of effectiveness in both their process and their outputs (Bardsley and Rogers 2010). For example, participants of a VRA process in South Australia were reportedly "disappointed" with their VRA Report, saying that the results could not (even) be used to specifically define which capacities to adapt, or specify levels of vulnerability (Bardsley and Rogers 2010). This resonates with experiences reported of community-based adaptation in rural Vanuatu which revealed situations where low levels of interest in the participatory activities were linked to where climate stress was not always judged to be a priority concern (Reid et al. 2009). Van Riet (2009) has also advised that the usefulness of local level risk assessments should be questioned due to the lack of what he terms 'thick descriptions' of the local context, and perceived risks to address the dynamic qualities of risk.

Such criticisms raised questions about the levels of participation of stakeholders in the VRA process. Resolving such criticisms was deemed increasingly important because the VRA process needs to be safeguarded to ensure that the current rapid up-scaling of climate change adaptation planning research and program activity has sound foundations in existing knowledge, and is responsive to local priorities that are most pertinent to the beneficiaries in question (Conway and Mustelin 2014). VRAs will thus need to use participatory methods to produce valid prioritizations of existing and future vulnerabilities. As such, they are now considered an important entry point for the participation of communities in adaptation planning, rather than as an end-product. They can, in principle, be instrumental in establishing who is, what is vulnerable and why they are vulnerable (Masundire et al. 2015), thus establishing firm foundations for the next stages of actual action. Conway and Mustelin (2014) identified three broadly defined areas deserving greater scrutiny for successful adaptation planning and implementation, namely: addressing priorities through participation; identifying appropriate entry points and actors; and ensuring effective delivery. They argue that these concerns, if not addressed, have the potential to hamper attempts at effective delivery and, in fact, to increase the vulnerability of intended beneficiaries of the adaptation agenda.

This perspective is supported by Geoghegan and Leyson (2012), who argue that climate change is a particular environmental discourse constructed through memory, observation and conversation, and in the quest to understanding how people understand it, complex and unquantifiable relationships with climate and landscape that people use to make sense of and 
respond to climate change should not continue to be excluded. Therefore, more attention must be paid to the ways in which communities define their shared experience, identity, values, and their way of life (Granderson 2014). He (Granderson 2014) argues that places are not only the sites through which weather and climate are encountered but where identity, values and institutions are anchored, and thus creating a challenge of how to incorporate this multiplicity of experiences, meanings and interests into risk decision-making for climate change in fair, transparent and culturally appropriate ways.

In summary, our literature review has highlighted several desired characteristics of VRAs centering on the increased importance of stakeholder participation, which have recently been argued as being key to improved and effective outcomes, and which need to be taken in to account in improvements and therefore in our evaluation tool. These include legitimacy (Travis and Bates 2014), place-based emphasis (Webler et al. 2016; Henstra 2017), local priorities (Bardsley and Rogers 2010; Conway and Mustelin 2014), shared values (Geoghegan and Leyson 2012; Granderson 2014), and stakeholder ownership (Yoseph-Paulus and Hindmarsh 2018). These build on some characteristics established previously such as stakeholder trust (Gunderson and Holling 2001), cross-scale links (Green 2004), representation of vulnerable groups (Adger 2006), active stakeholder engagement (Fussel 2007; Aalst et al. 2007), identification of current capacities/gaps (Fussel et al. 2006), entry points (Fussel et al. 2006), and gender responsiveness (Terry 2009). Consideration of all of these should be incorporated into any modern evaluation tool of VRA outcomes, across both processes and outputs: they are incorporated below.

\subsection{The increasing need for rigorous evaluation of VRAs}

The importance of vulnerability assessments seems to be increasing in both the fields of project development, and development, with climate adaptation slowly gaining relevance. Countries, especially developing nations, are increasingly aware of the potential risks that climate change threatens to their development ambitions as well as to hard-won progress already made in health, agriculture, tourism, energy and other sectors. Vulnerability risk assessments (VRAs) are now considered prerequisites for the construction of adaptation strategies and policies, as they provide information on the circumstances that create risk and the factors which would improve the resilience of local systems to respond to those risks (Davis et al. 2017). VRAs can thus also be used to drive decision-making on the investment of financial resources and time on projects aimed at addressing the impacts of climate change. This recent new emphasis and interest in vulnerability assessments raises their importance, and the criticality for them to yield useful, sound, and locally grounded processes and outcomes.

However, there is little formal evaluation of vulnerability assessment processes and outcomes, little motivation to do so, and apparent indifference in reports by current practitioners as to whether assessments results actually go onwards to inform decision-making at all (Thomalla et al. 2006). Part of this might be due to a lack of clarity by all agencies as to the primary role of VRAs. Local-level VRAs are often initiated so as to ultimately feed into district or even national climate adaptation plans. In many countries, there is a specially appointed ministry at national level which collects all input. However, VRAs are often synthesized at the district 
level, to emphasize the major vulnerabilities of the district, and sometimes packaged in order to present more synergy with the current funding packages available in specific areas like water, agriculture etc. At each level templates may be provided by the higher level, with an emphasis which changes depending on current political interests. Any 'envelope' of local vulnerabilities, with linked information across topics, is lost in these summaries. The UNFCCC encourages deeply participatory approaches at the local level so as to produce rich results which contain highly relevant, grounded information but the actual guidelines they provide are designed to be relevant for global data collection from the national level, and it is these which are currently being used, unhelpfully, in the field at village or district level. There are moves to try to develop new sieves and filters in these national templates so that more richness can be reported to the UNFCCC, but in fact that detail is already lost by then.

While the UNFCCC drives applications of VRAs from a global level, to encourage coordinated government-backed action, other actors are beginning to focus more on the apparent potential power of such VRAs to not only collect information on local vulnerabilities, but at the same time to stimulate an awareness locally, and simultaneously embed new systemic perspectives into wider planning. Here the problem of evaluation rears its head again, because VRAs carried out with this focus in mind would require special attention to the participatory methodologies employed, and the provision of opportunity for local systems thinking to develop, which might lead to improved, more integrated, planning. Aalst et al. (2007) highlight what they label as "little systematic effort" to evaluate the effectiveness of VRA methodologies, and particularly the effectiveness of the risk-reduction strategies they might lead to.

VRAs should ideally not be an end in themselves, but be linked to the identification, planning and prioritization of options for preventing and managing climate change risk or adapting to changing conditions (Hagenlocher et al. 2019). Therefore, Abrahamsson and Tehler (2013)'s assessments of the VRA documents by studying how they describe what might happen (risk scenarios), how likely it is that it happens, and what the consequences are, might not be sufficient. There is a risk here that communities are represented as passive recipients of global environmental change, where there is a failure to capture their dynamic ability to mediate such impacts, either through resisting or coping with change (Stonich 2000). Scenario-based adaptation planning might also perpetuate top-down interactions where communities are only receiving directions form higher levels of government. The suggested evaluation tool that is explained below couple dimensions of vulnerability (exposure, sensitivity and adaptive capacity) with elements of meaningful engagement, ownership, and relevance (Sethamo et al. 2019).

In the absence of clear guidance regarding how to undertake local VRAs, their primary role, or which methods are best suited for which contexts, VRAs will likely continue to be dominated by unjustified choices of methods, which could, in principle, actually inhibit effective learning and outcomes (Preston et al. 2008). Furthermore, if excellent innovations in VRA methodologies cannot be evaluated, for example, against traditional project-management types, they may fall out of use without even being recognized. 
In this paper we present the development and testing of an evaluation tool for VRAs which is designed to encompass VRA process and output (reports), so that all of the possible roles of VRAs mentioned above can be evaluated. After consideration of the literature as summarized in Section 1.2 above, the following VRA sub-themes were identified as a key set for incorporation into a VRA evaluation tool:

a) community ownership;

b) practitioners' improved understanding of the local community

c) understanding of local context (geographic \& vulnerabilities);

d) current capacities and gaps;

e) active participation;

f) representation of vulnerable groups and gender issues.

\section{Materials and Methods}

The results in the present paper build on our understanding that vulnerability risk assessment is both a process and an outcome. As a product, it seeks to establish the best available evidence associated with the current and future climate conditions and impacts, the adaptive capacity of targeted communities and organizations, and the potential programmatic options to address the resulting vulnerability (Wood et al. 2017). The approach we took to develop a useful VRA tool covering the characteristics listed above was as follows:

i. Design a VRA evaluation tool that captures the quality of the aspects, identified as a)f) from the literature above in section 1.3, taking place during the VRA process.

ii. Circulate the draft tool for expert appraisal.

iii. Establish the ease/difficulty of implementation of the tool via a test of the tool in the field, by evaluating, comparing, and scoring two very different types of VRA approaches.

iv. Discuss the overall usefulness, indicated by this study, of the VRA evaluation tool.

\subsection{Ensuring full scope of the VRA Evaluation Tool}

In designing the Tool, we paid particular attention to the full coverage of the key VRA requirement themes, a)-f), as derived and summarized above. Below in Table 1 we show how each of these were accounted for in the final Tool, notwithstanding that its final form emphasized user-friendliness and chronology. Numbers 1-13 represents the different questions found in the tool while the theme codes represent the extracted themes following the clustering of needs.

Table 1: Coverage of the key VRA desired themes a)-f) within the VRA Evaluation Tool questions. Although many of the questions reinforced ALL of the desired themes from the literature review in section $1.3, a)-f)(\sqrt{ })$, some were specifically designed to focus on them $(\sqrt{ } \sqrt{ })$.

\begin{tabular}{llllllllllllll}
\hline Theme Code/ Question number in & 1 & 2 & 3 & 4 & 5 & 6 & 7 & 8 & 9 & 10 & 11 & 12 & 13 \\
Tool
\end{tabular}




\begin{tabular}{|c|c|c|c|c|c|c|c|c|c|c|c|c|c|}
\hline $\begin{array}{l}\text { A. Enhancing community } \\
\text { ownership. }\end{array}$ & $\sqrt{ } \sqrt{ }$ & $\sqrt{ }$ & $\sqrt{ } \sqrt{ }$ & $\sqrt{ } \sqrt{ }$ & $\sqrt{ } \sqrt{ }$ & $\sqrt{ }$ & $\sqrt{ }$ & $\sqrt{ }$ & $\sqrt{ }$ & & $\sqrt{ }$ & $\sqrt{ }$ & $\sqrt{ }$ \\
\hline $\begin{array}{l}\text { B. Enhancing understanding of } \\
\text { community by VRA practitioner. }\end{array}$ & & $\sqrt{ }$ & $\sqrt{ }$ & $\sqrt{ }$ & $\sqrt{ }$ & $\sqrt{ }$ & $\sqrt{ }$ & $\sqrt{ } \sqrt{ }$ & $\sqrt{ }$ & $\sqrt{ } \sqrt{ }$ & $\sqrt{ } \sqrt{ }$ & $\sqrt{ }$ & $\sqrt{ }$ \\
\hline $\begin{array}{l}\text { C. Clarifying local context } \\
\text { (geographic \& vulnerabilities). }\end{array}$ & $\sqrt{ }$ & $\sqrt{ }$ & $\sqrt{ }$ & $\sqrt{ }$ & $\sqrt{ }$ & $\sqrt{ } \sqrt{ }$ & $\sqrt{ }$ & $\sqrt{ }$ & $\sqrt{ }$ & $\sqrt{ }$ & $\sqrt{ }$ & $\sqrt{ }$ & $\sqrt{ }$ \\
\hline D. Current capacities and gaps. & $\sqrt{ }$ & $\sqrt{ }$ & $\sqrt{ }$ & $\sqrt{ }$ & $\sqrt{ }$ & $\sqrt{ } \sqrt{ }$ & $\sqrt{ }$ & $\sqrt{ }$ & $\sqrt{ }$ & $\sqrt{ }$ & $\sqrt{ } \sqrt{ }$ & $\sqrt{ } \sqrt{ }$ & $\sqrt{ } \sqrt{ }$ \\
\hline E. Encouraging active participation. & $\sqrt{ }$ & $\sqrt{ }$ & $\sqrt{ }$ & $\sqrt{ } \sqrt{ }$ & $\sqrt{ }$ & $\sqrt{ }$ & $\sqrt{ } \sqrt{ }$ & $\sqrt{ } \sqrt{ }$ & $\sqrt{ } \sqrt{ }$ & $\sqrt{ }$ & $\sqrt{ }$ & $\sqrt{ }$ & $\sqrt{ }$ \\
\hline $\begin{array}{l}\text { F. Gender and Vulnerable groups' } \\
\text { representation. }\end{array}$ & $\sqrt{ }$ & $\sqrt{ } \sqrt{ }$ & $\sqrt{ } \sqrt{ }$ & $\sqrt{ }$ & $\sqrt{ }$ & $\sqrt{ }$ & & $\sqrt{ }$ & & & $\sqrt{ }$ & & $\sqrt{ }$ \\
\hline
\end{tabular}

\subsection{Testing the Evaluation Tool with 6 VRAs from Botswana}

A thorough testing of the tool was undertaken by using it to evaluate an emerging new type of VRA approach which claims improved engagement, denoted Type-B, against a more standard approach, denoted Type-A. Type-A VRAs follow the standard VRA methodology as in Masundire et al. (2015) where practitioners pre-research potentially relevant topics and then deliver a two-day participatory process with village stakeholders to identify and prioritize existing and future vulnerabilities, risks, capacities and ambitions that those stakeholders think should be considered in future adaptation planning. The ethical considerations for this work were pre-approved by the HSSE Research Ethics and Governance Committee of the University of Brighton, reference ID REGC-15-022.R1, and relevant research permits were obtained from government authorities in Botswana. All participants have confirmed informed consent.

Type-B VRAs were administered with a new approach which was first reported in an exploratory study by Sethamo et al. (2019) where a shared-values crystallization process called WeValue InSitu is undertaken as a pre-process to the standard VRA approach, with each part taking one day. There was no extra content about adaptation at all: it is an adaptation of a shared-values approach initially developed in 2008 (Podger et al. 2010) to help informal and civil society groups to better articulate the intangible, values-based aspects of their work together which were important to them, in their own terms. It involved stepped stages to learn how to articulate tacit shared knowledge: stages of photo elicitation, triggering of awareness of values-in-action, and the development of a very concrete bespoke local values framework covering all the dimensions of their work together. There is no emphasis on any specific strand of work such as adaptation planning. The Sethamo et al. (2019) study suggested that villagers achieved an increased sense of self-awareness in the values-based session, which seemed to facilitate them finding more relevance, and thus their deeper participation and ownership, in the subsequent standard-VRA process.

The four Type-B VRA reports that we use here for our Tool evaluation came from a recent experimental study (Sethamo \& Harder, in preparation) of that same approach, undertaken in the North East District in Botswana, labelled VRAs \#1,2,3,4. A fifth village was from the same 
set (nominated by the District Commissioner's office as being similar, non-atypical and currently in need of VRA for government purposes) and randomly selected as a control: it received only the standard VRA process: identical to the other four villages but without the shared-values pre-process. It's VRA report was labelled VRA\#5. For VRAs \#1-5 we thus already know from rich qualitative case study material that there are significant differences in the qualities of the Type-A and Type-B VRAs, and they are thus a useful test of the new Evaluation Tool developed here.

Lastly, to provide a further comparison, the report from a standard VRA but as delivered by a different team in Bobirwa District was also evaluated, labelled VRA \#6. The characteristics of the VRA processes for the six villages are summarized in Table 2. We also note one further difference: the last VRA\#6 involved the practitioner pre-researching the adaptation risks in the area in advance, and pre-identifying what he perceived as the priorities. This is common practice, because villagers are typically very slow to identify them during a VRA event, and this is seen as a valid way to speed up the process. But it is incompatible with the shared-values approach which centers on grounded and locally led identifications and priorities, and so no pre-prioritization was carried out for VRAs\#1-5, as shown in Table 2.

Table 2: Key characteristics of the VRA processes evaluated

\begin{tabular}{llllll}
\hline & & Process(es) & Practitioners & District & Pre-prioritization? \\
\hline TYPE-B & VRA\#1-4 & $\begin{array}{l}\text { Shared-values pre- } \\
\text { process } \\
\text { PLUS } \\
\text { Standard VRA }\end{array}$ & Sethamo^ & North & No \\
& & & East & \\
TYPE-A & VRA\#5' & Standard VRA & Sethamo^ & North East & No \\
& VRA\#6 & Standard VRA & Consortium* & Bobirwa & Yes \\
& & & & \\
\hline
\end{tabular}

'VRA\#5 was from a village randomly allocated from six equivalent ones provided by their District Committee. The other five were used for VRAs \#1-5 (Sethamo \& Harder, in preparation) ^ A co-author, previously working as VRA practitioner. Reported fully in Sethamo \& Harder, in preparation.

*Full VRA report is available publicly: Masundire et al., 2015.

Below we present the results of this work, followed by their discussion.

\section{Results}

\subsection{The Evaluation Tool as developed here}


The Evaluation Tool was designed to incorporate consideration of all the aspects derived from the literature in section 1.3 above, a)-f), but also to be easily usable by practitioners delivering VRAs. The Tool thus captures events chronologically, which means they would be less likely to be omitted or misremembered: activities before, during and after the VRA visit.

Secondly, the Tool was purposely designed to use vocabulary, which is typical of that in use by practitioners, who normally think in terms of stakeholder engagement, gender and resource mobilization.

Thirdly, since the Tool needs to cover all desired characteristics of VRAs, it was borne in mind that its checklist nature could automatically also serve also as a learning to support the capacitybuilding of the practitioner. The tedious nature of documentation for traditional VRAs is wellknown, causing mental fatigue for the practitioners, so some effort was also made to make the format of each response as efficient and natural as possible, within the boundaries of good reporting.

Table 3: The VRA Evaluation Tool developed in this work. It covers all of the 'desired' themes from the literature, a)-f), in vocabulary and chronology which is natural to the VRA practitioner (also called the 'VRA researcher'). It includes formatting for answers that guides the respondent as to the detail suggested.

\begin{tabular}{|c|c|c|c|}
\hline \multirow{4}{*}{$\begin{array}{l}\text { Before you } \\
\text { started the } \\
\text { VRA.... }\end{array}$} & \multicolumn{3}{|l|}{ 1. Setting Out } \\
\hline & Statement & $\mathbf{Y} / \mathbf{N}$ & Comments \\
\hline & $\begin{array}{l}\text { Did you obtain a government } \\
\text { permission to undertake the study? }\end{array}$ & & \\
\hline & $\begin{array}{l}\text { Did you have to satisfy any other } \\
\text { ethical requirements relevant to the } \\
\text { study }\end{array}$ & & \\
\hline & 2. Gender and Vulnerable group & repre & sentation \\
\hline & Statement & $\mathbf{Y} / \mathbf{N}$ & Comments \\
\hline & $\begin{array}{l}\text { There was a deliberate move for equal } \\
\text { representation of men and women. }\end{array}$ & & \\
\hline & $\begin{array}{l}\text { There was a deliberate move for } \\
\text { inclusion of vulnerable groups. }\end{array}$ & & \\
\hline & $\begin{array}{l}\text { Those representing vulnerable groups } \\
\text { were made aware of their role. }\end{array}$ & & \\
\hline & $\begin{array}{l}\text { Those representing women were made } \\
\text { aware of their role. }\end{array}$ & & \\
\hline $\begin{array}{l}\text { The VRA } \\
\text { process } \\
\text { (community }\end{array}$ & 3. Who was involved? & & \\
\hline
\end{tabular}




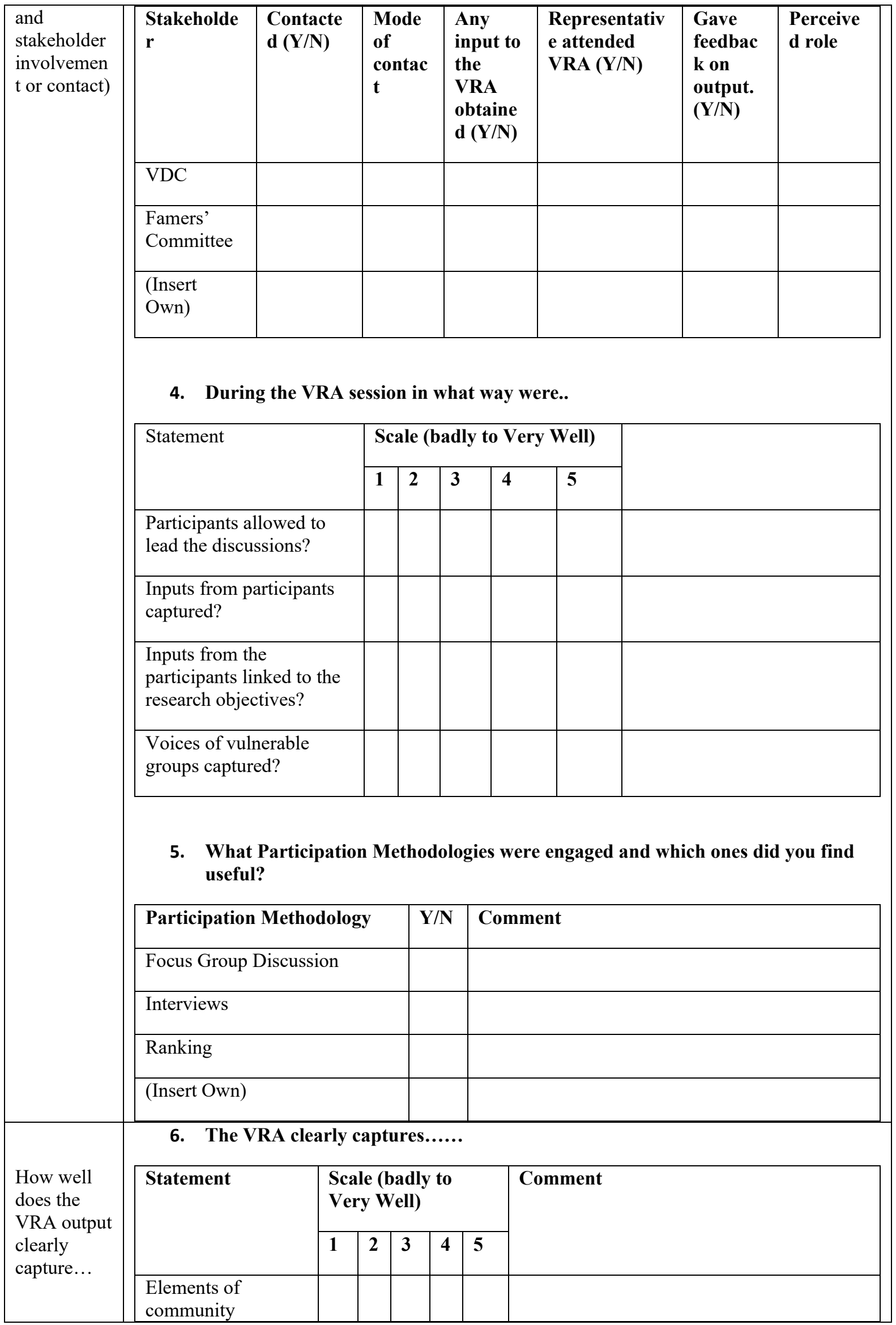




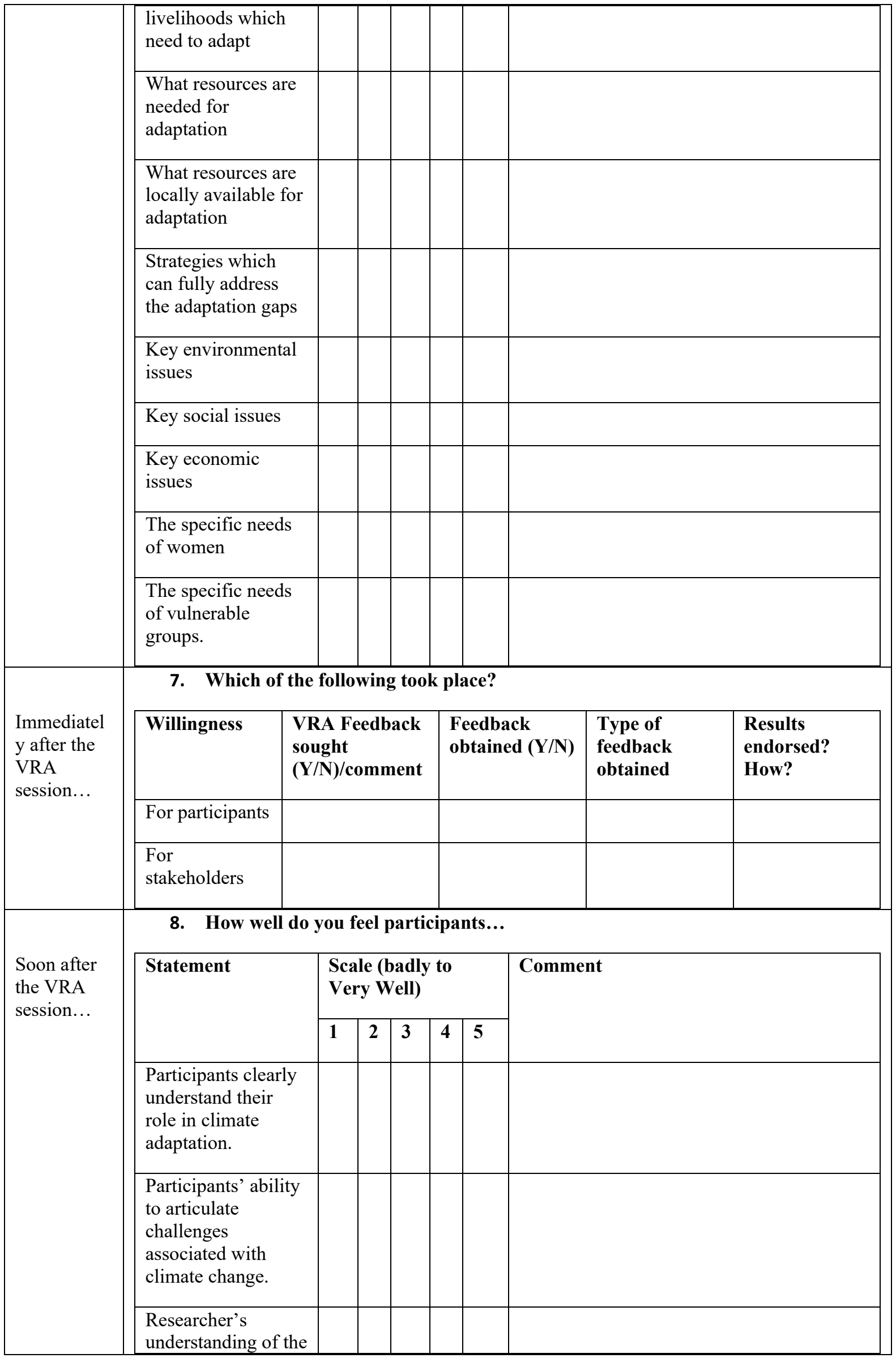




\begin{tabular}{|l|l|l|l|l|l|l|l|}
\hline & $\begin{array}{l}\text { community has } \\
\text { improved. }\end{array}$ & & & & & & \\
\hline $\begin{array}{l}\text { Participants' } \\
\text { understanding of the } \\
\text { need for the VRA. }\end{array}$ & & & & & & & \\
\hline $\begin{array}{l}\text { Participants are } \\
\text { engaging with the } \\
\text { VRA at their own } \\
\text { will. }\end{array}$ & & & & & & & \\
\hline $\begin{array}{l}\text { Felt the event was a } \\
\text { worthwhile use of } \\
\text { their time. }\end{array}$ & & & & & & & \\
\hline
\end{tabular}

9. What (do you think) is the likelihood of action that will follow? (only mark as relevant)

\begin{tabular}{|l|l|l|l|l|l|}
\hline Stakeholders & Nothing (1) & $\begin{array}{l}\text { Will think } \\
\text { about it (2) }\end{array}$ & $\begin{array}{l}\text { A lot of } \\
\text { discussions } \\
\mathbf{( 3 )}\end{array}$ & $\begin{array}{l}\text { Future } \\
\text { planning } \\
\mathbf{( 4 )}\end{array}$ & $\begin{array}{l}\text { Definite } \\
\text { engagement } \\
\text { (5) }\end{array}$ \\
\hline VDC & & & & & \\
\hline $\begin{array}{l}\text { Farmers' } \\
\text { Committee }\end{array}$ & & & & & \\
\hline Community & & & & & \\
\hline (Insert Own) & & & & & \\
\hline
\end{tabular}

10. What are the general outcomes you felt?

\begin{tabular}{|c|c|c|c|c|c|c|}
\hline \multirow[t]{2}{*}{ Statement } & \multicolumn{5}{|c|}{$\begin{array}{l}\text { Scale (badly to } \\
\text { Very Well) }\end{array}$} & \multirow[t]{2}{*}{ Comment } \\
\hline & 1 & 2 & 3 & 4 & 5 & \\
\hline \multicolumn{7}{|l|}{$\begin{array}{l}\text { Participants' } \\
\text { understanding of } \\
\text { climate change }\end{array}$} \\
\hline \multicolumn{7}{|l|}{$\begin{array}{l}\text { Participants' need to } \\
\text { adapt }\end{array}$} \\
\hline \multicolumn{7}{|l|}{$\begin{array}{l}\text { A feeling of } \\
\text { community/local } \\
\text { ownership of the } \\
\text { problem. }\end{array}$} \\
\hline \multicolumn{7}{|l|}{$\begin{array}{l}\text { A desire to lead } \\
\text { adaptation planning. }\end{array}$} \\
\hline $\begin{array}{l}\text { The researcher } \\
\text { obtained a } \\
\text { significant } \\
\text { understanding of the }\end{array}$ & & & & & & \\
\hline
\end{tabular}




\begin{tabular}{|c|c|c|c|c|c|c|c|}
\hline & $\begin{array}{l}\text { community and its } \\
\text { needs. }\end{array}$ & & & & & & \\
\hline \multirow{5}{*}{$\begin{array}{l}\text { Feedback } \\
\text { on the VRA } \\
\text { output... }\end{array}$} & \multicolumn{7}{|c|}{ 11. Community representation } \\
\hline & \multirow[t]{2}{*}{ Statement } & \multicolumn{5}{|c|}{$\begin{array}{l}\text { Scale (badly to } \\
\text { Very Well) }\end{array}$} & \multirow[t]{2}{*}{ Comment } \\
\hline & & 1 & 2 & 3 & 4 & 5 & \\
\hline & $\begin{array}{l}\text { To what extent do } \\
\text { you feel the VRA } \\
\text { represents the } \\
\text { community (needs)? }\end{array}$ & & & & & & \\
\hline & $\begin{array}{l}\text { That the community } \\
\text { would agree that the } \\
\text { VRA represents } \\
\text { their needs? }\end{array}$ & & & & & & \\
\hline
\end{tabular}

12. How relevant is the VRA to existing agendas?

\begin{tabular}{|l|l|l|l|l|l|l|}
\hline Statement & \multicolumn{3}{|l|}{$\begin{array}{l}\text { Scale (badly to } \\
\text { Very Well) }\end{array}$} & \multicolumn{2}{l|}{ Comment } \\
\cline { 1 - 5 } & $\mathbf{1}$ & $\mathbf{2}$ & $\mathbf{3}$ & $\mathbf{4}$ & $\mathbf{5}$ & \\
\hline $\begin{array}{l}\text { Village } \\
\text { Development Plan }\end{array}$ & & & & & & \\
\hline $\begin{array}{l}\text { District } \\
\text { Development Plan }\end{array}$ & & & & & & \\
\hline $\begin{array}{l}\text { National } \\
\text { Development Plan }\end{array}$ & & & & & & \\
\hline $\begin{array}{l}\text { Sustainable } \\
\text { Development Goals }\end{array}$ & & & & & & \\
\hline Sendai Framework & & & & & & \\
\hline Paris Agreement & & & & & & \\
\hline (Insert Own) & & & & & & \\
\hline
\end{tabular}

13. Which roles are needed for this VRA and at which level?

\begin{tabular}{|c|c|c|c|c|}
\hline \multirow[t]{2}{*}{ Role } & \multicolumn{3}{|c|}{$\begin{array}{l}\text { Insert the name of a } \\
\text { stakeholder where } \\
\text { appropriate. }\end{array}$} & \multirow[t]{2}{*}{ Comment } \\
\hline & Village & District & National & \\
\hline
\end{tabular}




\begin{tabular}{|l|l|l|l|l|l|}
\hline & & & & & \\
\cline { 2 - 6 } & Financier & & & & \\
\cline { 2 - 5 } & Implementer & & & & \\
\hline & (Insert Own) & & & & \\
\hline
\end{tabular}

\subsection{Evaluation Tool Appraisal by key vulnerability risk assessment professionals}

Our methodology for development of the Evaluation Tool included the appraisal of its prototype by professionals working for leading climate finance and adaptation planning organizations. This was undertaken during the Least Developed Countries Expert Group Training workshop on National Adaptation Plans which was held in Kenya, from the $1^{\text {st }}-6^{\text {th }}$ September 2019. This included members of the Adaptation Programme within the Climate Change Secretariat, experts from the United Nations Development Programme (UNDP) as well as representatives of the Botswana Government at the National Disaster Management Office. Respondents were asked whether the tool addresses the current challenges associated with VRAs, whether there is a need for it for adaptation planning, and what improvements will enhance its usability. In general, responses indicated that it was considered a welcomed innovation to drive the improvement of adaptation plans, which seems to address the challenge of how communities are empowered, and how they communicate and are heard throughout the VRA process timeline. Respondents emphasized that evaluating the VRA is necessary in order to ensure a reflective, holistic and equitable adaptation planning process. They highlighted that most of the adaptation projects that are brought through their organizations for funding fail to pass the appraisal because of a limited linkage with local communities. Practitioners advised that the tool should include provision for users of it to indicate their own ideas for VRA improvements, as this will allow field workers to think more about the levels of inclusivity they were achieving, in a way that stimulates them to consider more widely how to engage in a more inclusive and open-ended manner.

\subsection{Evaluation results}

In Table 4 below are the results obtained through the use of the VRA Evaluation Tool in six villages with VRAs labelled \#1-5 from the North East District, and \#6 from Bobirwa SubDistrict, in Botswana.

Table 4: Evaluation test results of the VRA Evaluation Tool carried out in six villages in Botswana.

VRA Type-B

(added shared-values pre-process)
VRA Type-A

(standard VRA) 


\begin{tabular}{rr|rrrrrrr} 
Max & 1 & 2 & 3 & 4 & 5 & 6 \\
& score & Score & Score & Score & Score & Score & Score \\
\hline
\end{tabular}

During the VRA session, in what way were... (Participants allowed to lead the discussions, Inputs from participants captured, Inputs from the participants linked to the research objectives, Voices of vulnerable groups captured)

The VRA clearly captures... (Elements of community livelihoods which need to adapt, What resources are needed for adaptation, What resources are locally available for adaptation, Strategies which can fully address the adaptation gaps, Key environmental issues, Key social issues, Key economic issues, The specific needs of women, The specific needs of vulnerable groups.)

How well do you feel participants... (Participants clearly understand their role in climate adaptation, Participants' ability to articulate challenges associated with climate change, Researcher's understanding of the community has improved, Participants' understanding of the needs of the research, Participants are engaging with the research at their own will, Felt the event was a worthwhile use of their time.)

What are the general outcomes you felt? (Participants' understanding of climate change, Participants' need to adapt, A feeling of community/local ownership of the problem, A desire to lead adaptation planning, The researcher obtained a significant understanding of the community and its needs.)

\section{Community representation}

(To what extent do you feel the VRA represents the community (needs)? That the community would agree that the VRA represents their needs?)

How relevant is the VRA to existing agendas?

(Village Development Plan, District Development Plan, National
20

19

19

18

19

15

14

45

45

35

43

44

40

18 
Development Plan, Sustainable

Development Goals, Sendai

Framework, Paris Agreement.)

\section{Total}

160

155

140

147

151

123

Table 4 presents evaluations of the both the process and the output of the VRAs. According to the evaluation, Type-B VRAs \#1-6 have the highest cumulative scores $(155,140,147,151)$ while both Type-A VRA \#5 and VRA \#6 have much lower scores $(123,88)$. Breaking these down, in terms of community development and how their inputs were captured the VRAs \#14 scored a high score of 19/20, while the VRAs \#5 -6 scored a 15. For how VRAs capture essential elements within the community e.g. key social issues and livelihoods that need to adapt, VRAs \#1 - 4 scored the maximum score of 45 and VRAs \#5 - 6 had a score of 40. For how participants understand their role in climate adaptation and their ability to articulate challenges, VRAs \#1 -4 registered a maximum score of 30 while VRAs \#5 -6 registered 24. For community representation, VRAs \#1 - 4 have a high perfect score of 10 while VRAs \#5 6 only earned 6 . In terms of relevance to local and international instruments, VRAs \#1 - 4 represented the highest relevance with scores between 24-26/30, while VRAs \#5-6 managed scores of 23 and 15 respectively.

\section{Discussion}

There is a high level of consistency within the results of the Evaluation Tool in Table 4 for both Type-A (standard) and Type-B (shared-values) VRAs, suggesting that the Tool gives a true reflection of the different natures of the two VRA processes and outputs.

With such an ability to discriminate the nature and quality of VRAs, the Evaluation Tool become very useful to support the development of relevant adaptation policies and adaptation action at the local level. It could help to address the problem of overgeneralization that is widespread. The ability to discriminate between stronger and weaker adaptation planning could be a contribution to improvement to the international climate response from local level adaptation plans, to nation adaptation plans. UNFCCC and aid organizations that provide funding could also more easily identify and then support improvements in national adaptation plans. When providing funding to countries, the Evaluation Tool could be useful to monitor that the planning processes are inclusive and participatory (Woodruff and Regan 2018).

Using the Evaluation Tool also allows more localized analysis of several topics. For example, practitioners are able to establish where ownership of action might be a challenge. Table 4 shows that VRA \#1-4 have high chances of community ownership of climate action, while VRA \#5 - 6 are lagging behind. There is also an indication that the WeValue approach assists participants to clearly identify how the impacts of climate change are going to manifest within the things that they care about as members of the community and as a local planning institute. This is consistent with Juarez and Brown, 2008, who caution that for adaptation to work participants must be willing to assume ownership of the process of developing adaptation actions. There is also a strong indication that community ownership is difficult to establish 
where communities cannot establish their role within the process of climate action as shown by the results of both VRA \#5 and \#6.

Table 4 also indicates that the researcher had difficulty with improving their understanding of the community in VRA \#5 and \#6. Cedergren et al. (2019) says that usually those leading the VRA do not have detailed knowledge of the day-to-day life of communities and as a result, this person (or group of persons) has limited ability to assess what the main risks and vulnerabilities are and, consequently, to produce a risk assessment with a high degree of validity. This has a potential to contributing to what Freudenburg (1996) terms 'blind spots' which are a result of the researcher's preconceived ideas and existing frames of reference. The results on Table 4 could indicate that the desktop reviews and literature reviews on the community which were undertaken in Type-A VRAs are not enough to build a comprehensive picture of the community. Table 4 indicates that the results of VRA \#5 and \#6 only provided a vague context. These seem to have largely disregarded local complexities that include the social, cultural, and other economic and political realities that drive systems (Kattumuri et al. 2017). Meanwhile the results from the Type-B VRAs \#1 - 4, where the WeValue process was used, seem to produce an enhanced contextual setting of these villages, as questions peculiar to these villages are answered. The results for VRA \#1 - 4 in Table 4 communicates that where context has been clarified participants easily identify with the results and can align some of their local activities with the results. It is within these villages, after the values-based process, where we see more vigor and eagerness to take up leadership role.

The Evaluation Tool also seems to be useful to provide insights as to why VRA approaches produce the results that they do. Table 4 indicates that in the Type-B approach, the WeValue session seems to unveil, or bring to the surface, information that can later be used as opportunities for mainstreaming adaptation within the village setup. This is consistent with O'Brien's (2012) conclusions that a group's vulnerability is not determined solely or primarily by climate, but rather by a range of social, economic, and political factors inherent to the system. During discussions of Type-B VRAs, village members wove in information of some of the projects that they are working with and those that are still being planned. This suggests a stepwise improvement in output compared to Type-A where outsiders need to pre-select the topics for discussion because the approach does not otherwise elicit an adequate range. This is a contribution to a long-desired goal of promoting not only local voices, but the voices of all in the room once they are drawn into the discussion via their shared values: this process naturally supports all voices present, which can then include women and vulnerable groups.

Lastly, the Evaluation Tool indicates that one type of VRA has stimulated participants to move closer to actually actioning the adaptation plans coming out of the process. This comes from the indications that participants in the Type-B VRAs have a stronger feeling of including climate change adaptation in their regular work, and believe that they are well placed to address the impacts of climate change in the village. If true, this could contribute to the change in the VRA rhetoric, where VRAs are increasingly viewed as potentially powerful tools of mobilization. There is also a visible change in the perception of their role in adaptation planning where in one of the Type-A VRAs, VDC members mentioned that "We should not wait for direction from outside, we should initiate things and see to it that they are implemented so that 
we can go forward" while in Type-B VRAs, VDC members struggled to connect the outputs of the VRAs with their current community needs. The evaluation results might support the idea that, since the Type-B, values-based VRA approach involved deep consideration and negotiation of local shared values, that this enabled village stakeholders to clarify the things that they care about, and possibly assisted them think more clearly about their responsibilities in climate action. This is only a potential insight, but the Evaluation Tool allows it to be shown, and leads to the suggestion that any causal links be investigated further. (A rigorous investigation of the results of the experiment versus control VRAs is in preparation (Sethamo \& Harder 2021), and the detailed analysed responses of the participants are expected to be placed in it's Supplementary Information.)

The results are also in line with outcomes of the appraisal that was undertaken by professional working within the field of climate finance and adaptation planning during the Least Developed Countries Expert Group Training workshop in Kenya. The results indicate a reflective, holistic and equitable adaptation planning process as emphasized by professionals. In summary, the Evaluation Tool has provided a clear indication of the several extra benefits of the Type-B approach, with a surprising level of conceptual detail, all by using a relatively simple template for practitioners to fill in, another requirement that was highlighted by the professionals. Finally, the results indicate that the tool improves upon some of the limitations of participatory vulnerability risk assessment by clarifying the degree to which people and the things that they value are exposed to climate variation or change, there is a clear indication of how this exposure can harm their livelihoods as well as the degree to which they could address the potential for harm by taking action to reduce or mitigate against exposure or sensitivity.

\section{Conclusion}

There has been a frustrating lack of progress in national adaptation plans, and their effective links to local plans, globally. Vulnerability Risk Assessments (VRAs) are considered a key technique for instigating adaptation planning, but global reports indicate systemic difficulties in the details of the approaches used, and in particular the ability to capture local context and related adaptation issues. Although there are no formalized evaluation systems for them, national and international agencies are reporting their quality is generally inadequate. After surveying current reports of weaknesses and gaps in VRAs, we developed, obtained expert advice on, and field-tested an Evaluation Tool. It is designed to be easily used by practitioners, yet to be useful for detailed conceptual analysis which can discriminate between weaker and stronger practice.

We demonstrated here the usefulness of this Evaluation Tool by testing it on an innovative VRA approach which uses a pre-process of crystallizing shared values of participants before considering climate issues. The results show that the tool can not only discriminate the quality of this approach compared to controls, but can also capture many district characteristics, and differences between them. In this case, it showed that the shared-values approach to VRAs produced very good results in terms of process and output, but also provided insights as to why this might be so, thus providing ideas for a further research agenda. 
Feedback form expert VRAs practitioners indicate that the Evaluation Tool is easy to use in the field, and could addresses critical gaps in the current VRA process through its 'checklist' chronological approach, which can double-up as a self-learning tool for users. This is particularly important in developing countries where adaptation planning capacity is still developing.

In short, we show here that the use the Evaluation Tool is useful for practitioners as a reporting aid, a self-learning checklist, and also as a discriminatory and analytical tool for identifying good and poor performance in considerable detail.

\section{Acknowledgements}

This work builds directly on work funded by the European Union's Seventh Framework Programme (Grant No. 212237) under the 'Research for the Benefit of Specific Groups: Civil Society Organizations', ESDinds.

\section{References}

Aalst, M., T. Cannon, and I. Burton. 2007. "Community level adaptation to climate change: The potential role of participatory community risk assessment." Global Environmental Change 18: 165 - 179. doi:10.1016/j.gloenvcha.2007.06.002

Abrahamsson, M., and H. Tehler. 2013. "Evaluating risk and vulnerability assessments: a study of the regional level in Sweden." International Journal of Emergency Management 9(1): 76. doi:10.1504/ijem.2013.054106

Adger, W. N. 2006. "Vulnerability." Global Environmental Change 16(3): 268281. doi:10.1016/j.gloenvcha.2006.02.006

Bardsley, D. K., and R. P. Geoffrey. 2010. "Prioritizing Engagement for Sustainable Adaptation to Climate Change: An Example from Natural Resource Management in South Australia." Society \& Natural Resources 24(1): 1-17. DOI: 10.1080/08941920802287163

Cedergren, A., V. H. Swaling, H. Hassel, C. Denward, K. M. Sonnek, P. Albinsson, J. Bengtsson and A. Sparf. 2019. "Understanding practical challenges to risk and vulnerability assessments: the case of Swedish municipalities.” Journal of Risk Research 22(6): 782-795. DOI: $\underline{10.1080 / 13669877.2018 .1485169}$

Conway, D., and J. Mustelin. 2014. "Strategies for improving adaptation practice in developing countries." Nature Climate Change 4: 339-342.

https://doi.org/10.1038/nclimate2199

Davis, C.L., K. Waagsaether, and N. Methner. 2017. "Development of a risk assessment methodology and vulnerability indices." In: Climate change over South Africa: From trends 
and projected changes to vulnerability assessments and the status quo of national adaptation strategies. Chapter 3 in the DEA, South Africa's 3rd National Communication to UNFCCC. Pretoria: Department of Environmental Affairs.

Dawson, T., S. Jackson, J. House, I. Prentice, and G. Mace. 2011. "Beyond Predictions: Biodiversity Conservation in a Changing Climate." Science 332(6025): 53 58. doi:10.1126/science. 1200303

Freudenburg, W R. 1996. "Risky Thinking: Irrational fears about Risk and Society." Annals of the American Academy of Political and Social Science 545(1): 44-53. https://doi.org/10.1177\%2F0002716296545001005

Fussel, H.-M., R. J. T. Klein, and K. L. Ebi. 2006. “Adaptation assessment for public health", In: Menne, B. and K. L. Ebi. (eds.), Climate Change and Adaptation Strategies for Human Health, Steinkopff Verlag, Darmstadt: 41-62.

Fussel, H.-M. 2007. "Vulnerability: A generally applicable conceptual framework for climate change research." Global Environmental Change 17(2): 155-

167. doi:10.1016/j.gloenvcha.2006.05.002

Geoghegan, H., and C. Leyson. 2012. "On climate change and cultural geography: farming on the Lizard Peninsula, Cornwall, UK." Climatic Change 113: 55-66.

https://doi.org/10.1007/s10584-012-0417-5

Granderson, A. A. 2014. "Making sense of climate change risks and responses at the community level: A cultural-political lens." Climate Risk Management 3: 5564. doi:10.1016/j.crm.2014.05.003

Green, C. 2004. "The evaluation of vulnerability to flooding", Disaster Prevention and Management 13(4): 323-329. https://doi.org/10.1108/09653560410556546

Gunderson, L., and C.S. Holling. (eds). 2001. "Panarchy: understanding transformations in human and natural systems." Washington (DC): Island Press

Hagenlocher, M., I. Meza, C. Anderson, A. Min, G. Renaud, Y. Walz, S. Siebert and Z. Sebesvari. 2019. "Drought vulnerability and risk assessments: state of the art, persistent gaps, and research agenda." Environmental Research Letters 14 (8): 1 - 14. doi:10.1088/17489326/ab225d

Hay, J. E., \& N. Mimura. 2013. "Vulnerability, Risk and Adaptation Assessment Methods in the Pacific Islands Region: past approaches, and considerations for the future." Sustainability Science 8(3): 391-405. doi:10.1007/s11625-013-0211-y

Henstra, D. 2017. "Climate Adaptation in Canada: Governing a Complex Policy Regime." Review of Policy Research 34(3): 378-399. doi:10.1111/ropr.12236 
IFRC. 2009. "Climate Change Adaptation Strategies for Local Impact Key Messages for UNFCCC Negotiators.” Retrieved from

https://unfccc.int/resource/docs/2009/smsn/igo/054.pdf

Intergovernmental Panel on Climate Change. 2007. "Climate Change 2007: Impacts, Adaptation and Vulnerability." Contribution of Working Group II to the Fourth Assessment Report of the Intergovernmental Panel on Climate Change, M.L. Parry, O.F. Canziani, J.P. Palutikof, P.J. van der Linden and C.E. Hanson, Eds., Cambridge University Press, Cambridge, UK, 976pp.

https://www.ipcc.ch/site/assets/uploads/2018/03/ar4_wg2_full_report.pdf

Juarez, J. A., and K. D. Brown. 2008. "Extracting or Empowering?: A Critique of Participatory Methods for Marginalized Populations.” Landscape Journal 27(2): 190204. doi:10.3368/1j.27.2.190

Kattumuri, R., D. Ravindranath, and T. Esteves. 2017. "Local adaptation strategies in semiarid regions: study of two villages in Karnataka, India." Climate and Development 9(1): 3649. DOI: $\underline{10.1080 / 17565529.2015 .1067179}$

Masundire, H., D. Morchain, N. Raditloaneng, S. Hegga, G. Ziervogel, C. Molefe, M. Angula, and K. Omari. 2015. "Vulnerability and Risk Assessment in Botswana's Bobirwa Sub-District: Fostering People-Centred Adaptation to Climate Change.” IDRC: Collaborative Adaptation Research Initiative in Africa and Asia.

O’Brien, K. 2012. “Global environmental change II: From adaptation to deliberate transformation." Progress in Human Geography 36: 667676.doi:10.1177/0309132511425767

Podger, D., G. Piggot, M. Zahradnik, S. Janoušková, I. Velasco, T. Hak, A. Dahl, A. Jimenez, M. K. Harder. 2010. "The Earth Charter and the ESDinds Initiative." Journal of Education for Sustainable Development 4(2): 297-305. doi:10.1177/097340821000400219

Preston, B. L., C. Brooke, T. G. Measham, T. F. Smith, and R. Gorddard. 2008. "Igniting change in local government: lessons learned from a bushfire vulnerability assessment." Mitigation and Adaptation Strategies for Global Change 14(3): 251283. doi:10.1007/s11027-008-9163-4

Reid, H., M. Alam, R. Berger, T. Cannon, S. Huq, and A. Milligan. 2009. "Community-based adaptation to climate change: an overview." In: Ensor, J. and R. Berger. (Eds), Understanding Climate Change Adaptation: Lessons from Community-Based Approaches. Practical Action: $11-30$.

Romieu, E., T. Welle, S. Schneiderbauer, M. Pelling, and C. Vinchon. 2010. "Vulnerability assessment within climate change and natural hazard contexts: revealing gaps and synergies through coastal applications." Sustainability Science 5(2): 159-170. doi:10.1007/s11625-0100112-2 
Ribot, J. C. 2010. "Vulnerability does not just Fall from the Sky: Toward Multi-scale Propoor Climate Policy," in Robin Mearns and Andrew Norton (eds.), Social Dimensions of Climate Change: Equity and Vulnerability in a Warming World. Washington DC: 45 - 74 The World Bank.

Sethamo, O. A., R. J. Masika and M. K. Harder. 2019. "Understanding the role of crystallizing local shared values in fostering effective community engagement in adaptation planning in Botswana." Climate and Development. DOI: 10.1080/17565529.2019.1639488

Small-Lorenz, S., L. Culp, T. Ryder, T. Will, and P. Marra. 2013. "A blind spot in climate change vulnerability assessments." Nature Climate Change 3(2): 91-93.

doi:10.1038/nclimate1810

Stonich, S. 2000. "The human dimensions of climate change: the political ecology of vulnerability." Chap. 7 in Global Environmental Change: Research Pathways for the Next Decade. National Academy Press.

Terry, G. 2009. "No climate justice without gender justice: an overview of the issues." Gender \& Development 17(1): 5-18. DOI: 10.1080/13552070802696839

Thomalla, F., T. Downing, E. Spanger-Siegfried, G. Han, and J. Rockström. 2006. "Reducing hazard vulnerability: towards a common approach between disaster risk reduction and climate adaptation." Disasters 30(1): 39-48. doi:10.1111/j.1467-9523.2006.00305.x

Travis, W. R., and B, Bates. 2014. "What is climate risk management?” Climate Risk Management 1: 1-4. doi:10.1016/j.crm.2014.02.003

UNFCCC. 2018. "Report by the Least Developed Countries Expert Group in collaboration with the Adaptation Committee, Summary of progress in the process to formulate and implement national adaptation plans.' Retrieved from

https://unfccc.int/sites/default/files/resource/06e.pdf

Van Riet, G. 2009. "Disaster risk assessment in South Africa: Some current challenges." South African Review of Sociology 40(2): 194-208. doi:10.1080/21528586.2009.10425108

Warrick, O. 2007. "Development, forest conservation and adaptation to climate change: a case for integrated community-based sustainability in rural Vanuatu." In Proceedings, the Australian New Zealand Society for Ecological Economics Conference "Reinventing Sustainability: a Climate for Change’', Queensland, Australia, 3-6 July 2007

Webler, T., S. Tuler, K. Dow, J. Whitehead and N. Kettle. 2016. "Design and evaluation of a local analytic-deliberative process for climate adaptation planning." Local Environment 21(2): 166-188. DOI: $10.1080 / 13549839.2014 .930425$

Westerhoff, L., and B. Smit. 2009. "The rains are disappointing us: dynamic vulnerability and adaptation to multiple stressors in the Afram Plains, Ghana." Mitigation and Adaptation Strategies for Global Change 14(4): 317-337. doi:10.1007/s11027-008-9166-1 
Wood, L., A. Apotsos, P. Caffrey, and K. Gibbs. 2017. "Fostering uptake: lessons from climate change vulnerability assessments in Africa and Latin America." Development in Practice 27(4): 444-457. DOI: $\underline{10.1080 / 09614524.2017 .1303034}$

Woodruff, S. C., and P. Regan. 2018. "Quality of national adaptation plans and opportunities for improvement." Mitigation and Adaptation Strategies for Global

Change. doi:10.1007/s11027-018-9794-z

Yoseph-Paulus, R., and R. Hindmarsh. 2018. "Addressing inadequacies of sectoral coordination and local capacity building in Indonesia for effective climate change adaptation." Climate and Development 10(1): 35-48. DOI: $\underline{10.1080 / 17565529.2016 .1184609}$ 